\title{
Comparing welfare estimates across stated preference and uncertainty elicitation formats for air quality improvements in Nairobi, Kenya
}

\author{
HILARY NDAMBIRI \\ Centre for Environmental Economics and Policy in Africa (CEEPA), \\ University of Pretoria, Pretoria 002, Republic of South Africa. \\ Email:ndambirihk@yahoo.com
}

ROY BROUWER

Department of Environmental Economics, Institute for Environmental Studies (IVM), Vrije Universiteit, Amsterdam, De Boelelaan 1087, $1081 \mathrm{HV}$ Amsterdam, The Netherlands.

Email: roy.brouwer@vu.nl

ERIC MUNGATANA

Centre for Environmental Economics and Policy in Africa (CEEPA), University of Pretoria, Pretoria 002, Republic of South Africa.

Email: eric.mungatana@up.ac.za

Submitted 4 February 2014; revised 1 February 2015, 3 September 2015; accepted 25 November 2015; first published online 17 February 2016

\begin{abstract}
The effect of preference uncertainty on estimated willingness to pay (WTP) is examined using identical payment cards and alternative uncertainty elicitation procedures in three split samples, focusing on air quality improvement in Nairobi. The effect of the stochastic payment card (SPC) and polychotomous payment card (PPC) are compared with a conventional payment card (PC). Substantial financial support is found for improved air quality in Nairobi, with approximately 85 per cent of the whole sample stating a positive WTP. The way WTP values are elicited, with and without ability to express preference uncertainty, has significant effect on WTP welfare estimate. Allowing respondents to express experienced uncertainty when stating WTP value yields more conservative but less accurate WTP values for inclusion in policy analysis. The PPC seems to hold more promise since it is easier to understand and imposes less cognitive burden on survey participants than the SPC in a developing country context.
\end{abstract}

Financial support from the Centre for Environmental Economics and Policy in Africa (CEEPA), University of Pretoria, Republic of South Africa, and the Centre for International Cooperation (CIC), Vrije Universiteit Amsterdam, The Netherlands, is gratefully acknowledged. 


\section{Introduction}

Stated preference (SP) elicitation procedures in non-market valuation have been challenged by their hypothetical nature and are due to, among others, respondent unfamiliarity with many of the environmental goods and services involved, subject to substantial preference uncertainty (Champ and Bishop, 2001; Alberini et al., 2003; Brouwer, 2011). While some degree of preference uncertainty can be taken away by providing respondents with more information, or allowing them to gain more experience in making unfamiliar choices and value statements, some preference uncertainty has been argued always to remain as a result of the existence of incomplete, fuzzy preference structures, and the cognitive burden often imposed on participants in SP surveys (e.g., Wang, 1997; van Kooten et al., 2001; Shaikh et al., 2007).

Several procedures have been introduced since the mid-1990s to capture the degree of preference uncertainty in SP research. Overviews of these approaches are provided in several places (e.g., Ready et al., 1995; Ekstrand and Loomis, 1998; Samnaliev et al., 2006; Shaikh et al., 2007; Akter et al., 2008; Martínez-Espiñeira and Lyssenko, 2012), and vary from ex post decision ratings to polychotomous choice formats to indicate the level of certainty respondents place on valuation bids. Other procedures used to deal with respondents' preference uncertainty include payment cards, which show possible value ranges to help respondents identify their values and match respondent valuation bids against a combination of numerical certainty scale ratings or ordinal categories reflecting the degree of experienced choice uncertainty. The former numerical certainty scales have been referred to as stochastic payment cards (SPC) in the literature (e.g., Wang, 1997; Wang and Whittington, 2005), as opposed to deterministic payment cards (PC) without the ability to explicitly rate one's preference uncertainty (e.g., Rowe et al., 1996). Here we will refer to the latter ordinal certainty scale as the polychotomous payment card (PPC), following the terminology used for similar alternative willingness to pay (WTP) elicitation formats (e.g., Johannesson et al., 1998; Welsh and Poe, 1998; Samnaliev et al., 2006; Chang et al., 2007).

An important unresolved methodological issue in the SP literature remains, in that various studies examining the impact of these approaches on WTP, in particular using different combinations of WTP and uncertainty elicitation formats, have come up with different results, making it hard, if not impossible, to conclude which of these approaches is preferred, in particular for practical policy and decision making. While some studies report that a certain preference uncertainty calibration method yields higher and more efficient WTP welfare estimates, others report more conservative and less efficient WTP values (Petrolia and Kim, 2011). There is yet another group of studies that has found no significant differences between the valuation formats that account for preference uncertainty (e.g., Vossler et al., 2003). Often, a wide range of different WTP elicitation and uncertainty elicitation formats are applied in these existing studies. As a result, these $\mathrm{SP}$ research findings may not give reliable policy signals for informed decision making. Several authors have therefore argued in favor of more comparative analysis of alternative formats for investigating preference 
uncertainty so as to facilitate our improved understanding of its effects in non-market valuation. For that reason, the main objective of this paper is to add to the empirical evidence base and compare the WTP welfare estimates elicited from three different types of payment cards: the ordinary PC without any reference to preference uncertainty, the SPC and the PPC, with an application to the valuation of air quality improvements from traffic emission reductions in Nairobi, Kenya. Although several SP studies exist related to improved air quality in major cities around the world, particularly in developing countries such as Beijing (Wang et al., 2006; Du and Mendelsohn, 2011) and Manila in the Philippines (Fabian and Vergel, 2002), none of these studies explicitly accounts for preference uncertainty. An exception is the study by Wang and Whittington (2000), who valued an air pollution control program in Sofia, Bulgaria, applying a single bound dichotomous choice WTP question and a SPC. The former produced significantly higher mean WTP values than the latter, but it is not possible to attribute this to SP uncertainty due to the use of two different WTP elicitation formats. In this study, we assess the impact of preference uncertainty on stated WTP while controlling for the role of the WTP elicitation format by using one and the same payment card.

The remainder of this paper is organized as follows. Section 2 presents the research methodology in more detail and is followed by a description of the case study area and the data collection procedure in section 3 . Section 4 presents the main results and section 5 concludes.

\section{Methodological framework}

\subsection{Survey design}

The survey consisted of three main parts. The first part included easy warm-up questions eliciting respondents' general awareness, perception and knowledge of air pollution in Nairobi, including questions about how far they live from the main road and whether or not they own a motorized vehicle. This was followed in the second part by the introduction of a plan for the reduction of emission levels from motorized vehicles in the city of Nairobi and respondents' WTP for such a plan. The third and final part of the survey contained questions related to respondents' sociodemographic and economic household characteristics. In this section, we focus mainly on the presentation of the public good in question (air quality improvement), and the WTP and preference uncertainty elicitation formats. This is then followed in the section 2.2 by a discussion of the underlying econometric models.

The emission reduction plan for the city of Nairobi was explained to respondents, as in most SP studies focusing on air quality improvements in big cities (e.g., Wang and Mullay, 2006; Wang and Zhang, 2008), in text only, without any visual aids, as for instance in Shechter and Kim (1991). From the pretests, it became clear that respondents' overall awareness of air pollution from motorized traffic is very high, making it relatively easy to convey the implications of current and possible future emission levels and reductions thereof to respondents. Respondents were informed about current emission levels of different toxic gases - carbon monoxide (CO), 
sulphur oxides $\left(\mathrm{SO}_{\mathrm{x}}\right)$, nitrogen oxides $\left(\mathrm{NO}_{\mathrm{x}}\right)$, hydrocarbons $\left(\mathrm{CH}_{\mathrm{x}}\right)$, lead $(\mathrm{Lb})$ and particulate matter $\left(\mathrm{PM}_{\mathrm{x}}\right)$ - from both public and private transportation vehicles, and the impacts of these emissions on human health in general terms such as risk of respiratory illnesses. Reference was made to the reduced visibility in the early morning and late evening as a result of the dark-colored smoke coming out of the vehicles' exhaust pipes, and also the discoloration of buildings alongside the main roads and in the vicinity of the main bus stops in the city.

After this, an emission control program for the city of Nairobi was presented, emphasizing the need for more regulation and monitoring of motorized vehicles on the roads in Nairobi by the City Council's Directorate of Motor Vehicle Inspections (DMVI), including more strict control over the import of old cars from abroad. Respondents were informed that such intensified regulation and inspection of motorized vehicles require additional funding. The current budget of the DMVI does not suffice to impose stricter measures to meet existing air quality standards in Nairobi. Additional funding will be needed for more effective and improved regulatory capacity.

Next, respondents were asked whether they would be willing to contribute to a special trust fund to finance the required additional regulatory power in order to effectively reduce current emission levels from motorized transportation. To this end, a special trust fund would be introduced to which respondents could contribute on a voluntary basis, as this appeared to be the most preferred payment vehicle compared to increased income taxation, public transportation costs for those who do not own a motorized vehicle, or increased fuel costs for private vehicles. Although such a voluntary trust fund may induce free riding and possibly lack incentive compatibility as argued by Carson and Groves (2007), alternative payment vehicles such as those mentioned above evoked considerable protest response during the pretest, and were therefore considered inappropriate. Respondents were informed that the money in the special trust fund would be used exclusively to effectively reduce emission levels. Also, the link to the City Council's DMVI and its role in regulating and monitoring urban traffic was expected to increase the credibility of the policy scenario and the effective use of the payment. Finally, respondents were asked to answer as truthfully as possible and imagine they actually would contribute to the trust fund, ensuring that their decision was perceived as having real consequences for their disposable household budget (Carson and Groves, 2007).

Three different payment cards were used in three split samples to elicit WTP to reduce current emission levels in Nairobi and improve air quality. The bid amounts on these cards were based on the pretest survey. This pretest generated 15 of such bids, ranging from KSh0-2,000. The three different cards are reproduced in the appendix to this paper. Using a conventional PC (e.g., Rowe et al., 1996), respondents were presented with an ordered range of values and asked to tick the highest amount that they would be willing to pay for the improvement of air quality. Maximum WTP was assumed to be equal to or greater than the ticked value, but less than the next higher value (Cameron and Huppert, 1989). All respondents 
in the three split samples were asked the same following valuation question:

Suppose the presented policy to reduce emissions from motorized vehicles and improve air quality in the city of Nairobi will actually be implemented and reduce the current amount of emissions, what is the maximum amount of money you would be willing to pay one-off to the special trust fund to achieve this? (tick or circle a single amount on the card).

Since this elicitation format does not account for preference uncertainty, it was used as the control group with which the subsequent two preference and preference uncertainty elicitation formats were compared.

In the SPC version, respondents were offered the same range of values, but this time accompanied by probabilities ranging from zero to one, headed under five ordinal certainty scales: 'definitely yes', 'probably yes', 'not sure', 'probably no' and 'definitely no'. For every value presented on the payment card, respondents were asked to select the probability that they would actually pay the specific amount shown. This way the certainty of WTP responses is explicitly embedded in the analysis by allowing respondents to express their degree of preference certainty related to each bid amount (Wang, 1997). The elicitation format takes an individual's valuation of the proposed environmental improvement as a random variable with an associated distribution rather than a single point value as in conventional PC responses. Respondents who were presented the SPC were asked the following valuation question:

Suppose the presented policy to reduce emissions from motorized vehicles and improve air quality in the city of Nairobi will actually be implemented and reduce the current amount of emissions, how certain are you that you would actually one-off pay the amounts of money shown on this card to the special trust fund to achieve this? (tick or circle your level of certainty to pay each of the amounts on the card).

Finally, in the PPC elicitation format, respondents were again presented with the same range of values as before, but this time only with the five ordinal levels related to their preference uncertainty. Using this format respondents are still allowed to explicitly express their level of certainty about each bid amount on the payment card, but based on five instead of 11 uncertainty levels. The valuation question was in this case identical to the one for the SPC. An important advantage of these latter two value elicitation approaches is that besides allowing respondents to simultaneously express their level of certainty when considering various bid amounts, it circumvents possible starting point bias and some of the difficulties inherent in the process of bid selection (Welsh and Poe, 1998). This increases the precision of the estimated parameters and central tendency estimates (Wang and He, 2011). An important disadvantage of the payment cards is that they have been shown to introduce possible range and midpoint bias (e.g., Ryan et al., 2004). However, because we use identical cards in this study across the three split samples, if present, this possible bias is expected to impact value estimates in the same way across the three treatments. 


\subsection{Econometric models and hypothesis testing}

The different elicitation formats generate interval and discrete choice data or combinations thereof, and were therefore analyzed using interval and random effects probit regression models. Starting with the interval regression model, this model is based on the underlying assumption that a respondent's true maximum WTP is at least as high as the amount crossed on the payment card, but less than the next highest amount listed on the card (Cameron and Huppert, 1989). Suppose the WTP function for the respondent is specified as:

$$
\log \left(W T P_{i}\right)=x_{i}^{\prime} \beta+\varepsilon_{i},
$$

where WTP is the latent dependent variable, $x_{i}$ is a vector of explanatory variables, $\beta$ the associated regression coefficients, and $\varepsilon_{i}$ is a normally distributed random variable with zero mean and variance $\sigma^{2}$. Suppose furthermore that an individual's true value, $W T P_{i}$, is known to lie within the interval $\left(Q_{i}, Q_{i+1}\right)$, then the probability distribution would be:

$$
\operatorname{Prob}\left(Q_{i} \leq W T P_{i} \leq Q_{i+1}\right) .
$$

For left-censored data for which a lower bound is not known, the probability distribution would be:

$$
\operatorname{Prob}\left(W T P_{i} \leq Q_{i+1}\right)
$$

and for right-censored data for which an upper bound is not known, it would be:

$$
\operatorname{Prob}\left(Q_{i} \leq W T P_{i}\right)
$$

This also implies that the $\log \left(W T P_{i}\right)$ lies between $\log \left(Q_{i}\right)$ and $\log \left(Q_{i+1}\right)$. Each pair of individual thresholds for $\log \left(W T P_{i}\right)$ could then be standardized to show that the probability that respondent $i$ will select a WTP amount $w_{i}$ is:

$$
\operatorname{Prob}\left(w_{i}\right)=\varpi\left(\frac{\log Q_{i}-x_{i} \beta}{\sigma}\right)-\varpi\left(\frac{\log Q_{i+1}-x_{i}^{\prime} \beta}{\sigma}\right),
$$

where $\varpi$ is the cumulative standard normal density function. The log likelihood function for a sample of independent observations can be written as:

$$
\log L=\sum_{i=1}^{n} \log \left[\varpi\left(\frac{\log Q_{i}-x_{i} \beta}{\sigma}\right)-\varpi\left(\frac{\log Q_{i+1}-x_{i}^{\prime} \beta}{\sigma}\right)\right] .
$$

Under the assumption that the stochastic term is normally distributed, both $\beta$ and $\sigma$ can be estimated and used to calculate the mean and median WTP:

$$
\begin{aligned}
\text { Mean WTP } & =e^{\left(x_{i}^{\prime} \beta+\sigma^{2} / 2\right)} \\
\text { Median WTP } & =e^{\left(x_{i}^{\prime} \beta\right)} .
\end{aligned}
$$

In this case, $x_{i}^{\prime}$ is taken as the vector of mean values of the explanatory variables, $\beta$ is the vector of estimated coefficients, and $\sigma$ is the estimated error variance. 
In the case of the SPC and the PPC, respondents are asked a series of choices such that more than one observation is collected from each individual. Respondents are asked to indicate their level of payment certainty for each of the bid amounts presented on the payment cards, and this leads to the generation of panel data observations where individual-specific variation remains fixed across the discrete choices. Consequently, a random parameter model is chosen to analyze these choice data, following, for example, Loomis (1997) and Imaz et al. (2014). The panel data regression model for the policy proposal on vehicular emission reductions can be formulated as follows:

$$
z_{i j}^{*}=x_{i j}^{\prime} \varphi_{j}+\varepsilon_{i j}=x_{i j}^{\prime} \varphi_{j}+\mu_{i}+v_{i j},
$$

where the dependent variable $z_{i j}^{*}$ is the measurable component of respondent preference uncertainty comprising the probability scores for the certainty levels of the bid amounts associated with the air quality improvement, $x_{i j}^{\prime}$ is a $1 \times k$ vector of individual respondent characteristics, $\varphi_{j}$ is a $k \times 1$ vector of associated variable coefficients, and $\varepsilon_{i j}$ is the error term which comprises, in this case, the random error due to variation among respondents (person-specific variation) $\mu_{i}$ and the random error due to random variation across discrete choices (differences among observations) $v_{i j}$. These error terms are assumed to be normally distributed with a mean of zero and variance of $\sigma_{u}^{2}$ and $\sigma_{v}^{2}$, respectively. While $z_{i j}^{*}$ is not observable, the binary part $z_{i j}$ can be observed, meaning that an individual respondent would be uncertain about paying a given bid amount if the WTP associated with the air quality improvement is less than the bid amount that has to be paid. Thus:

$$
\begin{aligned}
& z_{i j}=1 \text { if } W_{i j} \leq B I D \\
& z_{i j}=0 \text { otherwise. }
\end{aligned}
$$

The probabilistic discrete choice model can therefore be specified as:

$$
z_{i j}=\operatorname{Prob}\left(x_{i j} \varphi_{j}+\varepsilon_{i j} \leq B I D\right) .
$$

Although the random effects model can be estimated either as a logit or probit model, the probit specification is in this case employed due to its popularity in discrete choice data analysis, deriving from the fact that the two error terms of the model have identical distributions which allow simple functional forms for the estimators (Wooldridge, 2002).

Based on the three different value and preference uncertainty elicitation formats used in the study in three split samples, four hypotheses were formulated and tested. These are listed below.

$$
\begin{gathered}
H_{0}^{1}: w t p_{i r}^{P C}-w t p_{i r}^{S P C}=0 \\
H_{0}^{2}: w t p_{i r}^{P C}-w t p_{i r}^{P P C}=0 \\
H_{0}^{3}: w t p_{i r}^{S P C}-w t p_{i r}^{P P C}=0 \\
H_{0}^{4}: w t p_{r e}^{S P C}-w t p_{r e}^{P P C}=0
\end{gathered}
$$


The first three hypotheses compare the estimated mean WTP values from the three different SP elicitation formats using the same interval regression (ir) estimation procedure, thus allowing us to conclude whether the inclusion of explicit preference uncertainty elicitation procedures has a significant effect on stated WTP. The last hypothesis compares the same estimated mean WTP values based on the SPC and PPC, but this time using the random effects $(r e)$ probit model.

\section{Study area and data collection}

Nairobi, the capital city of Kenya, is found in the southeastern part of the country. The metropolitan area covers approximately $696 \mathrm{~km}^{2}$, and is located at an altitude varying between 1,600 and 1,850 m above sea level (CBS, 2009). The city is home to about 8 per cent of the country's total population and 25 per cent of Kenya's urban population (CBS, 2009). Population growth in Nairobi has been immense over the past five decades, from just over 343,000 in 1962 to about 3.1 million in 2009 and an expected 3.8 million in 2015 (CBS, 2009). Important driving factors behind this population growth include better economic prospects and market access, opportunities for higher education, and higher wage employment (NEMA, 2010). The rapid increase in population has led to an unprecedented sprawl of informal settlements, increased motorized traffic and corresponding impacts on air quality in the city. In addition, the difference between the resident (more than 3.1 million) and daytime populations (more than 4.2 million) implies an enormous amount of motorized traffic every day into and out of the city. Traffic growth has thus been singled out as the major source of air pollution in Nairobi, accounting for about 90 per cent of the total emissions into the air (Odhiambo et al., 2010). According to a study by Kinney et al. (2011), the city has high concentrations of toxic gases, such as $\mathrm{CO}, \mathrm{SO}_{x}, \mathrm{NO}_{x}, \mathrm{CH}_{4}, \mathrm{Lb}$ and $\mathrm{PM}_{x}$. As a result, many Nairobi residents are exposed to elevated concentrations of vehicular emissions, which pose serious long-term human health risks (Vliet and Kinney, 2007; Odhiambo et al., 2010; Kinney et al., 2011). Vehicle emission levels and the potential impact on human health have been measured in these existing studies, but so far no studies have been carried out measuring public perception of air quality problems in Nairobi to inform policy and decision making related to urban planning and traffic management.

A large-scale survey was carried out in the eight administrative divisions that form the city of Nairobi (CBS, 2009) after thorough pretesting of the survey instrument. The pretest served, among others, to establish the range of bid values for the payment cards. In the final survey, Nairobi residents over the age of 18 were interviewed in person by trained interviewers in the local language on the main streets in these eight administrative units on a random 'next to pass' basis, aiming to end up with a representative sample of the population in Nairobi as a whole. Respondents were randomly assigned to one of the three WTP elicitation formats, and an attempt was made to have a more or less equal distribution of respondents over the three formats. In total, 1,460 interviews were fully completed, divided over three split samples of 488 (PC), 480 (SPC) and 492 (PPC) respondents. 


\section{Results}

\subsection{Sample characteristics}

The main sociodemographic and economic sample characteristics are presented in table 1 . Most respondents (64 per cent) were male, aged between 31 and 40 years, with secondary education, coming from an average household size of three people, and living in the urban part of Nairobi (57 per cent). Mean annual disposable income of the respondents ranged between KSh20,000 and KSh30,000. Although the distribution of respondents across the eight administrative units is representative for the city as a whole, we are unable to conclude so about household income due to the lack of reliable statistical data for Nairobi. Most respondents (63 per cent) stated that they are confident that their future income will remain at its current level. Although only a small share of the sample population (17 per cent) owns a motor vehicle, most respondents reside close (150-200 m) to nearby main roads. The outcome of the Kruskal-Wallis chi-square test statistic in table 1 shows that the three split samples differ significantly in terms of household income, education level, household size, residing in the urban area, certainty of future income, and the distance respondents live to nearby roads, meaning that these factors have to be controlled for in the computation of the WTP welfare estimates.

The study also attempted to assess respondents' awareness and perception of air pollution and health risks. Awareness levels are very high. However, although 88 per cent of the respondents correctly defined air pollution as the contamination of the air they breathe with toxic smoke and dust particles, and 71 per cent was aware of the impacts on people's respiratory system, 12 per cent thought it was mainly about bad odor from decaying waste and smoke. Moreover, contrary to the available statistical data, only 55 per cent of the respondents identified motor vehicles as the main source of air pollution in Nairobi, followed by factories ( 25 per cent), the burning of waste by households (19 per cent) and peri-urban farming activities (5 per cent). Almost all respondents agreed that air pollution is a big problem in Nairobi that had to be more effectively addressed by the local authorities. Among the possible solutions, respondents identified the use of improved quality fuels, fuel-efficient motor vehicles, improved road infrastructure, and traffic regulation and control.

\subsection{Mean WTP across value and preference uncertainty elicitation formats}

WTP responses across the different payment card values and corresponding bid intervals are presented in table 2, distinguishing between the three preference and uncertainty elicitation formats. Overall, 84 per cent of all respondents supported the proposed emission control program and stated a positive WTP. The most frequently ticked WTP values on the payment cards are KSh50, 100, 200, 400 and 500 (by 50 per cent of the respondents). Ten per cent of the responses fall in the three highest bid intervals. Those stating a zero WTP were asked why in order to identify possible protest response. Based on these reasons, 10 per cent of all the responses were classified as protest, and 6 per cent as legitimate zero bidders. The most important protest reasons were that car owners should pay or that air quality was the responsibility of the government. Following common practice 
Table 1. Sociodemographic sample characteristics across the three samples with different preference elicitation formats

\begin{tabular}{|c|c|c|c|c|c|c|c|c|c|c|}
\hline \multirow[b]{2}{*}{ Variable } & \multicolumn{2}{|c|}{$P C$} & \multicolumn{2}{|c|}{$S P C$} & \multicolumn{2}{|c|}{$P P C$} & \multicolumn{2}{|c|}{ Whole sample } & \multicolumn{2}{|c|}{ Kruskal-Wallis test } \\
\hline & Mean & S.E. & Mean & S.E. & Mean & S.E. & Mean & S.E. & Chi-square & p-value \\
\hline Share male respondents & 0.62 & 0.02 & 0.64 & 0.02 & 0.65 & 0.02 & 0.64 & 0.01 & 0.73 & 0.694 \\
\hline Respondent age (1-6) & 3.04 & 0.05 & 3.07 & 0.04 & 3.16 & 0.04 & 3.09 & 0.02 & 4.18 & 0.123 \\
\hline Education level (1-5) & 3.61 & 0.05 & 3.34 & 0.04 & 3.47 & 0.04 & 3.47 & 0.03 & 17.02 & 0.000 \\
\hline Household income (1-7) & 2.86 & 0.07 & 2.58 & 0.06 & 2.77 & 0.06 & 2.73 & 0.04 & 8.41 & 0.015 \\
\hline Household size (1-6) & 3.49 & 0.06 & 3.79 & 0.05 & 3.60 & 0.05 & 3.63 & 0.03 & 21.93 & 0.000 \\
\hline Share living in urban area & 0.69 & 0.02 & 0.52 & 0.02 & 0.51 & 0.02 & 0.57 & 0.01 & 34.98 & 0.000 \\
\hline Distance to nearby main road (1-6) & 4.78 & 0.08 & 3.83 & 0.07 & 4.42 & 0.06 & 4.34 & 0.04 & 26.13 & 0.000 \\
\hline Share owning motorized vehicle & 0.18 & 0.02 & 0.16 & 0.02 & 0.19 & 0.02 & 0.17 & 0.01 & 2.03 & 0.362 \\
\hline Share certain about future income & 0.83 & 0.02 & 0.52 & 0.02 & 0.54 & 0.02 & 0.63 & 0.01 & 31.23 & 0.000 \\
\hline
\end{tabular}

Notes: S.E., standard error; PC, payment card; SPC, stochastic payment card; PPC, polychotomous payment card.

Age categories: $1=18-20 ; 2=21-30 ; 3=31-40 ; 4=41-50 ; 5=51-60 ; 6=$ over 60 years.

Education levels: $1=$ no education; $2=$ primary school; $3=$ secondary school; $4=$ tertiary education; $5=$ university degree.

Income levels: $1=$ less than KSh10,000; $2=10,001-20,000 ; 3=20,001-30,000 ; 4=30,001-40,000 ; 5=40,001-50,000 ; 6=50,001-60,000$; $7=$ more than KSh60,000.

Household size: $1=$ one member; $2=$ two members; $3=$ three members; $4=$ four members; $5=$ five members; $6=$ more than five members.

Distance: $1=$ less than $50 \mathrm{~m} ; 2=51-100 \mathrm{~m} ; 3=101-150 \mathrm{~m} ; 4=151-200 \mathrm{~m} ; 5=201-250 \mathrm{~m} ; 6=$ over $251 \mathrm{~m}$. 
Table 2. WTP responses across the three preference elicitation formats

\begin{tabular}{|c|c|c|c|c|c|c|c|c|c|}
\hline \multirow[b]{2}{*}{ Bids (KSh) } & \multirow[b]{2}{*}{ Bid interval } & \multicolumn{2}{|c|}{$P C$} & \multicolumn{2}{|c|}{$S P C$} & \multicolumn{2}{|c|}{$P P C$} & \multicolumn{2}{|c|}{ Whole sample } \\
\hline & & Freq. & $\%$ & Freq. & $\%$ & Freq. & $\%$ & Freq. & $\%$ \\
\hline Protest & - & 53 & 11 & 35 & 7 & 57 & 12 & 145 & 10 \\
\hline 0 & $0-25$ & 18 & 4 & 28 & 6 & 46 & 9 & 92 & 6 \\
\hline 25 & $25-50$ & 16 & 3 & 8 & 2 & 79 & 16 & 103 & 7 \\
\hline 50 & $50-70$ & 30 & 6 & 60 & 13 & 65 & 13 & 155 & 11 \\
\hline 75 & 70-100 & 26 & 5 & 30 & 6 & 24 & 5 & 80 & 5 \\
\hline 100 & 100-150 & 57 & 12 & 46 & 10 & 35 & 7 & 138 & 9 \\
\hline 150 & $150-200$ & 18 & 4 & 24 & 5 & 16 & 3 & 58 & 4 \\
\hline 200 & $200-250$ & 39 & 8 & 46 & 10 & 37 & 8 & 122 & 8 \\
\hline 250 & $250-300$ & 38 & 8 & 30 & 6 & 24 & 5 & 92 & 6 \\
\hline 300 & $300-400$ & 28 & 6 & 24 & 5 & 30 & 6 & 82 & 6 \\
\hline 400 & $400-500$ & 33 & 7 & 60 & 13 & 32 & 7 & 125 & 9 \\
\hline 500 & $500-800$ & 61 & 13 & 34 & 7 & 24 & 5 & 119 & 8 \\
\hline 800 & 800-1000 & 34 & 7 & 32 & 7 & 11 & 2 & 77 & 5 \\
\hline 1000 & 1000-1500 & 33 & 7 & 8 & 2 & 12 & 2 & 53 & 4 \\
\hline 1500 & 1500-2000 & 4 & 1 & 15 & 3 & 0 & 0 & 19 & 1 \\
\hline Total & & 488 & 100 & 480 & 100 & 492 & 100 & 1460 & 100 \\
\hline
\end{tabular}

Notes: PC, payment card; SPC, stochastic payment card; PPC, polychotomous payment card.

in the CV literature (e.g., Strazzera et al., 2003; Dziegielewska and Mendelsohn, 2007), these protest responses were omitted from further analysis, while the true zero votes were kept in. ${ }^{1}$ This yields a total of 1,315 useable responses. The distributions of these WTP responses across the three elicitation formats excluding the protest response are significantly different at the 1 per cent level (the Kolmogorov-Smirnov test results are available from the authors upon request).

Based on these WTP responses, mean WTP values were estimated, including their standard errors and 95 per cent confidence intervals based on bootstrapping in Stata 13 (table 3), in order to test the hypotheses presented in section 2.2. $T$-tests are used to test the equality of the estimated mean WTP values. The mean WTP values estimated using interval regression are all significantly different from one another, with the elicitation formats accounting for preference uncertainty generating lower WTP values than the conventional PC without addressing preference uncertainty. ${ }^{2}$

${ }^{1}$ No significant differences were detected between protest and non-protest respondents in a simple logit regression analysis regressing respondent participation in the contingent market on a number of sociodemographic respondent characteristics, implying the absence of selection bias.

${ }^{2} T$-statistics are $6.917(p<0.01), 8.641(p<0.01)$ and $1.900(p<0.06)$, respectively, when comparing mean WTP based on the PC and the SPC, the PC and the PPC, and the SPC and the PPC elicitation format. The $t$-test statistic is 5.600 ( $p<0.001$ ) when comparing the SPC and PPC mean WTP values based on the random effects probit models. 
Table 3. Estimated mean WTP values (KSh/household) for improved air quality in Nairobi based on different preference and uncertainty elicitation formats and estimation procedures

\begin{tabular}{|c|c|c|c|c|c|}
\hline & $P C_{i r}$ & $S P C_{i r}$ & $P P C_{i r}$ & $S P C_{r e}$ & $P P C_{r e}$ \\
\hline Mean WTP & 396.6 & 246.5 & 213.6 & 364.9 & 346.5 \\
\hline S.E. & 18.1 & 12.7 & 11.8 & 2.9 & 1.7 \\
\hline $\begin{array}{l}95 \% \text { confidence } \\
\text { intervals }\end{array}$ & $361.1-432.0$ & 221.7-271.4 & 190.4-236.9 & $330.8-397.4$ & $303.3-387.9$ \\
\hline $\begin{array}{l}\text { Number of } \\
\text { observations }\end{array}$ & 435 & 445 & 435 & 445 & 435 \\
\hline
\end{tabular}

Notes: PC, payment card; SPC, stochastic payment card; PPC, polychotomous payment card; $i r$, interval regression; $r$, random effects probit regression.

Of the two payment cards addressing preference uncertainty, the PPC format generates the lowest mean WTP. The same result is found when comparing mean WTP estimates based on the random effects probit model in table 3. Here too, the PPC format yields the lowest mean WTP of the two uncertainty preference elicitation formats.

In order to assess the implications of accounting for preference uncertainty on the efficiency of the WTP welfare estimates, the relative measure of variation (RMV) was calculated by dividing the difference between the upper and lower bound 95 per cent confidence interval by mean WTP (e.g., Loomis and Ekstrand, 1998). Based on the interval regression estimates, the RMV is slightly higher for the uncertainty elicitation formats $(0.20$ and 0.22 for the SPC and PPC formats, respectively) than for the conventional PC (0.18), implying that the reduction in welfare estimate due to preference uncertainty is at the expense of statistical efficiency. Consistent results are found when calculating the variation coefficients (standard errors divided by mean WTP) across the preference and uncertainty elicitation formats. The RMV values are also higher for the lower PPC WTP than the SPC WTP based on the random effects probit model.

\subsection{Explaining willingness to pay}

Interval regression was also used to estimate the relationship between respondents' WTP and a number of sociodemographic respondent characteristics. The results are presented in table 4 . As before, a distinction is made between the three different preference and uncertainty elicitation formats. Explanatory factors that are significant across all three elicitation formats are household disposable income, respondent certainty about the household's future income, and whether or not the respondent owns a motorized vehicle. The first two variables influence stated WTP in a positive way, as expected, with respondents belonging to higher income groups and respondents who are certain about their future income stating on average a higher WTP. Respondents who own a motorized vehicle such as a car or motor are willing to pay on average significantly less to a special trust fund to reduce emission levels and improve air quality. A possible explanation for this negative relationship is that these respondents may prefer 
to invest directly in their own motorized vehicle, such as a filter on the exhaust pipe or improved fuel use efficiency of their motors.

A respondent's age has a negative influence on stated WTP in all three models, implying that younger respondents are willing to pay on average more than older respondents, but this variable is only statistically significant in the estimated models based on the PC and SPC, not the PPC. Also, the distance respondents live from the nearest main road has a negative impact in all three models, implying distance decay, as respondents who live nearer to the main road are expected to benefit most from a reduction in emission levels, but this variable is only significant for the two elicitation formats that account for preference uncertainty. Finally, men are willing to pay on average significantly more than women in all three models, but only significantly so in the model based on the conventional PC. A possible explanation for this positive effect is that men often decide on financial matters in a household and control the household budget. Access to information and therefore higher awareness levels has been suggested as another possible explanation in the specific context of air quality in both developed and developing countries (Carlsson and Johansson-Stenman, 2000; Wang and Zhang, 2008).

\subsection{Explaining preference uncertainty}

In order to also examine what factors determine preference uncertainty, a random effects probit model was estimated relating the certainty scores expressed in the SPC and the PPC elicitation formats to the same sociodemographic and other respondent characteristics as before. The results are presented in table 5 for the two different uncertainty elicitation formats. The random effects model accounts for the cross-sectional nature of the available data, i.e., the fact that every respondent indicated for every payment card value how certain (s)he was that (s)he would actually pay the specific amount of money. This gives more than 6,000 observations per model based on 435 and 445 respondents. The dependent variable in this case is a binary variable representing preference uncertainty. The categories 'not sure', 'probably no' and 'probably yes' are recoded as uncertain responses and given the value 1 . The 'definitely yes' and 'definitely no' responses were regarded as certain responses and given the value 0 .

Sociodemographic explanatory factors common to both models are household income, distance to the nearest main road and whether the respondent owns a motorized vehicle. The latter two variables have a positive impact on preference uncertainty, meaning that the likelihood that a respondent is uncertain about his or her WTP response increases as respondents live further away from the main road or own a car. The reverse relationship is found for household income. Here, the likelihood of being uncertain about WTP decreases as respondents earn more money. A respondent's certainty about his or her future income level also has a negative relationship with preference uncertainty (respondents who trust their income to stay at least the same as before are less likely to be uncertain about their stated WTP), but is only statistically significant in the model based on the SPC. A similar relationship between income and preference uncertainty is reported in Brouwer (2011). In the same model, older men 


\begin{tabular}{|c|c|c|c|c|c|c|}
\hline \multirow[b]{2}{*}{ Explanatory factor } & \multicolumn{2}{|c|}{$P C$} & \multicolumn{2}{|c|}{$S P C$} & \multicolumn{2}{|c|}{$P P C$} \\
\hline & $\begin{array}{c}\text { Coefficient } \\
\text { estimate }\end{array}$ & S.E. & $\begin{array}{c}\text { Coefficient } \\
\text { estimate }\end{array}$ & S.E. & $\begin{array}{c}\text { Coefficient } \\
\text { estimate }\end{array}$ & S.E. \\
\hline Constant & $3.885^{* * *}$ & 0.216 & $3.452^{* * *}$ & 0.207 & $4.133^{* * *}$ & 0.415 \\
\hline Gender $(1=$ male; $0=$ female $)$ & $0.374^{* * *}$ & 0.014 & 0.019 & 0.302 & 0.048 & 0.254 \\
\hline Age $(1-6)$ & $-0.116^{* * *}$ & 0.008 & $-0.190^{* * *}$ & 0.015 & -0.038 & 0.198 \\
\hline Household income (1-7) & $0.530^{* * *}$ & 0.021 & $0.483^{* * *}$ & 0.039 & $0.304^{* * *}$ & 0.021 \\
\hline Distance to nearby main road (in meters) & -0.021 & 0.257 & $-0.167^{* * *}$ & 0.011 & $-0.111^{* *}$ & 0.017 \\
\hline Owner of motorized vehicle $(1=$ yes; $0=$ no $)$ & $-0.191^{*}$ & 0.032 & $-0.352^{* *}$ & 0.068 & $-0.524^{* * *}$ & 0.046 \\
\hline Certain of future income $(1=$ yes; $0=$ no $)$ & $0.194^{*}$ & 0.039 & $0.634^{* * *}$ & 0.057 & $0.444^{* * *}$ & 0.031 \\
\hline Log likelihood & -996.25 & & -1040.48 & & -1068.02 & \\
\hline Likelihood ratio (LR) chi-squared (6 d.o.f.) & 282.32 & & 186.91 & & 53.15 & \\
\hline$p>$ LR chi-squared & 0.001 & & 0.001 & & 0.001 & \\
\hline Number of observations & 435 & & 445 & & 435 & \\
\hline
\end{tabular}

Notes: PC, payment card; SPC, stochastic payment card; PPC - polychotomous payment card.

${ }^{*} p<0.1$; $^{* *} p<0.05$; *** $p<0.01$. 
Table 5. Random effects probit regression results explaining stated preference uncertainty

\begin{tabular}{|c|c|c|c|c|}
\hline \multirow[b]{2}{*}{ Explanatory factor } & \multicolumn{2}{|l|}{$S P C$} & \multicolumn{2}{|l|}{$P P C$} \\
\hline & $\begin{array}{l}\text { Coefficient } \\
\text { estimate }\end{array}$ & S.E. & $\begin{array}{l}\text { Coefficient } \\
\text { estimate }\end{array}$ & S.E. \\
\hline Constant & 0.057 & 0.517 & $-1.089^{* *}$ & 0.554 \\
\hline $\begin{array}{l}\text { Gender }(1=\text { male; } \\
0=\text { female })\end{array}$ & $-0.408^{*}$ & 0.214 & -0.091 & 0.237 \\
\hline Age (1-6) & $-0.243^{*}$ & 0.148 & -0.077 & 0.134 \\
\hline $\begin{array}{l}\text { Household income } \\
\quad(1-7)\end{array}$ & $-1.287^{* * *}$ & 0.121 & $-0.606^{* * *}$ & 0.113 \\
\hline $\begin{array}{l}\text { Area of residence } \\
\quad(1=\text { urban; } \\
0=\text { peri-urban })\end{array}$ & -0.292 & 0.202 & -0.323 & 0.224 \\
\hline $\begin{array}{l}\text { Distance to nearby } \\
\text { main road (in } \\
\text { meters) }\end{array}$ & $0.345^{* * *}$ & 0.068 & $0.171^{* *}$ & 0.087 \\
\hline $\begin{array}{l}\text { Owner of motorized } \\
\text { vehicle }(1=\text { yes; } \\
0=\text { no })\end{array}$ & $0.999 * * *$ & 0.341 & $0.978^{* * *}$ & 0.364 \\
\hline $\begin{array}{l}\text { Certain of future } \\
\text { income }(1=\text { yes; } \\
0=\text { no })\end{array}$ & $-0.971^{* * *}$ & 0.206 & -0.343 & 0.233 \\
\hline Bid level (KSh) & $0.012^{* * *}$ & $4.25 \mathrm{e}-05$ & $0.009^{* * *}$ & $2.97 \mathrm{e}-04$ \\
\hline Bid level-squared & $-3.86 \mathrm{e}-06^{* * *}$ & $1.75 \mathrm{e}-07$ & $-2.86 \mathrm{e}-06^{* * *}$ & $1.31 \mathrm{e}-07$ \\
\hline Log likelihood & -1682.42 & & -1976.01 & \\
\hline $\begin{array}{l}\text { Wald chi-squared } \\
\text { (9 d.o.f.) }\end{array}$ & 900.40 & & 1083.49 & \\
\hline$p>$ chi-squared & 0.001 & & 0.001 & \\
\hline $\begin{array}{l}\text { Number of } \\
\text { observations }\end{array}$ & 6675 & & 6525 & \\
\hline $\begin{array}{l}\text { Number of } \\
\text { respondents }\end{array}$ & 445 & & 435 & \\
\hline
\end{tabular}

Notes: PC, payment card; SPC, stochastic payment card; PPC, polychotomous payment card.

${ }^{*} p<0.1{ }^{* *} p<0.05 ;{ }^{* * *} p<0.01$.

are also less likely to be uncertain than women. The impact of age on preference uncertainty is just significant at the 10 per cent level. Akter et al. (2009) and Brouwer (2011) find the same relationships between respondent sex and age and preference uncertainty.

Finally, like Loomis and Ekstrand (1998), Brouwer (2011) and Logar and van den Bergh (2012), the study confirms the presence of a U-shaped relationship between preference uncertainty and the bid value respondents are asked to pay. The significant positive impact of bid level on preference uncertainty indicates that a higher (lower) bid value results, all else being equal, in a higher (lower) likelihood of being uncertain. The significant 
negative quadratic effect of the bid level implies that there is a range of values in between the lower and higher bids where respondents are more likely to be uncertain. This is likely to be the range where a respondent's true WTP is located.

\section{Conclusions and recommendations}

The study presented here aimed to examine the effect of preference uncertainty in SP research on estimated WTP welfare estimates. The existing valuation literature is ambivalent about the effect of controlling for preference uncertainty in SP studies, with some finding a higher and others a lower welfare estimate. Similar results are found for the statistical efficiency of the WTP welfare estimates. We control for the possible influence of the preference elicitation format and use an identical payment card containing the same range of values, and add different preference uncertainty elicitation procedures. The effect of two such preference uncertainty elicitation treatments on stated WTP, the SPCd and a polychotomous uncertainty approach are analyzed in split samples, using the conventional PC without any reference to preference uncertainty as a control group. A major advantage of the approaches presented here is that we circumvent arbitrary recoding procedures often used in the CV literature where uncertain yes responses to certain bid amounts are converted into no responses. Given the hypothetical nature of SP research, and the lack of familiarity with paying for public environmental goods, respondents are expected to experience considerable uncertainty when participating in SP surveys. This may substantially affect welfare estimation in policy analysis. In this study we focused on a pollution control program targeting toxic emissions from motorized vehicles in Nairobi, Kenya to improve air quality in one of the fastest growing metropolitan cities in sub-Saharan Africa.

The study shows that there exists substantial financial support for improved air quality in Nairobi, with approximately 85 per cent of the whole sample stating a positive WTP and protest being limited to 10 per cent. The way in which these WTP values are elicited, with and without the ability to express preference uncertainty, has a significant effect on the final welfare estimate to be included in policy analysis. This study confirms findings most commonly reported in the literature that accounting for preference uncertainty significantly reduces estimated WTP (e.g., Ekstrand and Loomis, 1998; Samnaliev et al., 2006; Chang et al., 2007; Brouwer, 2011). However, less obvious is to what extent this also produces more or less efficient welfare estimates. In this study, we show that allowing respondents to express the experienced (un)certainty that they will actually pay the stated WTP values also yields less efficient WTP values, implying less accurate value estimates for inclusion in policy analysis. More specifically, mean WTP is reduced by 38 per cent when applying the SPC compared to the conventional PC and by 46 per cent when comparing the PPC with the PC. The corresponding level of WTP imprecision increases by 13 and 22 per cent, respectively. Although other WTP elicitation formats have been argued to be more incentive compatible, the payment card and the open-ended WTP elicitation formats have been shown to produce the most 
conservative WTP estimates in the SP literature. As shown in this study, these estimates are reduced even further when accounting for preference uncertainty, and hence provide an important lower bound with which the implementation costs of the motorized emission reduction program in Nairobi can be compared. For application in a developing country context with a considerable share of illiterate survey participants, the PPC approach furthermore seems to hold most promise as it is easier to understand and imposes less of a cognitive burden on survey participants than the SPC. However, more similar valuation studies will be needed to arrive at a final conclusion.

\section{References}

Akter, S., J. Bennett, and S. Akhter (2008), 'Preference uncertainty in contingent valuation', Ecological Economics 67(3): 345-351.

Akter, S., R. Brouwer, L. Brander, and P. van Beukering (2009), 'Respondent uncertainty in a contingent market for carbon offsets', Ecological Economics 68(6): 1858-1863.

Alberini, A., K. Boyle, and M. Welsh (2003), 'Analysis of contingent valuation data with multiple bids and response options allowing respondents to express uncertainty', Journal of Environmental Economics and Management 45(1): 40-62.

Brouwer, R. (2011), 'A mixed approach to payment certainty calibration in discrete choice welfare estimation', Applied Economics 43(17): 2129-2142.

Cameron, T.A. and D.D. Huppert (1989), 'OLS versus ML estimation of nonmarket resource values with payment card interval data', Journal of Environmental Economics and Management 17(3): 230-246.

Carlsson, F. and O. Johansson-Stenman (2000), 'Willingness to pay for improved air quality in Sweden', Journal of Applied Economics 32(6): 661-669.

Carson, R.T. and T. Groves (2007), 'Incentive and informational properties of preference questions', Environmental and Resource Economics 37(1): 181-210.

CBS (2009), Economic Survey for 2009, Central Bureau of Statistics, Nairobi.

Champ, P.A. and R.C. Bishop (2001), 'Donation payment mechanisms and contingent valuation: an empirical study of hypothetical bias', Environmental and Resource Economics 19(4): 383-402.

Chang, J.I., S.H. Yoo, and S.J. Kwak (2007), 'An investigation of preference uncertainty in the contingent valuation study', Applied Economic Letters 14(9): 691-695.

Du, X. and R.O. Mendelsohn (2011), 'Estimating the value of the reduction in air pollution during the Beijing Olympics', Environment and Development Economics 16(6): 735-749.

Dziegielewska, D.A. and R.O. Mendelsohn (2007), 'Does "No" mean "No"? A protest methodology', Environmental and Resource Economics 38(1): 71-87.

Ekstrand, E.R. and J.B. Loomis (1998), 'Incorporating respondent uncertainty when estimating willingness to pay for protecting critical habitat for threatened and endangered fish', Water Resources Research 34(11): 3149-3155.

Fabian, H.G. and K.N. Vergel (2002), 'Analysis of air pollution exposure of individuals in the road environment', National Centre for Transportation Studies, College of Engineering, University of the Philippines, Manila.

Imaz, A., K.N.M. Habib, A. Shalaby, and A.O. Indris (2014), 'Investigating factors affecting transit user loyalty', Journal of Public Transport 7(1): 39-60.

Johannesson, M., B. Liljas, and P.-O. Johansson, (1998), 'An experimental comparison of dichotomous choice contingent valuation questions and real purchase decisions', Applied Economics 30(5): 643-647. 
Kinney, P.L., M. Gatari, N. Volavka-Close, et al. (2011), 'Traffic impacts on $\mathrm{PM}_{2.5}$ air quality in Nairobi, Kenya', Environmental Science and Policy 14(4): 369-378.

Logar, I. and J.C. van den Bergh (2012), 'Respondent uncertainty in contingent valuation of preventing beach erosion: an analysis with a polychotomous choice question', Journal of Environmental Management 113: 184-193.

Loomis, J.B. (1997), 'Panel estimators to combine revealed and stated preference dichotomous choice data', Journal of Agricultural and Resource Economics 22(2): 233-245.

Loomis, J.B. and E. Ekstrand (1998), 'Alternative approaches for incorporating respondent uncertainty when estimating willingness to pay: the case of the Mexican spotted owl', Ecological Economics 27(1): 29-41.

Martínez-Espiñeira, R. and N. Lyssenko (2012), 'Alternative approaches to dealing with respondent uncertainty in contingent valuation: a comparative analysis', Journal of Environmental Management 93(1): 130-139.

NEMA (2010), State of the Environment Report for Kenya, National Environment Management Authority, Nairobi.

Odhiambo, G.O., A.M. Kinyua, C.K. Gatebe, and J. Awange (2010), 'Motor vehicles air pollution in Nairobi, Kenya', Research Journal of Environmental and Earth Sciences 2(4): 178-187.

Petrolia, D.R. and T.G. Kim (2011), 'Contingent valuation with heterogeneous reasons for uncertainty', Resource and Energy Economics 33(3): 515-526.

Ready, R., J. Whitehead, and G.C. Blomquist (1995), 'Contingent valuation when respondents are ambivalent', Journal of Environmental Economics and Management 29(2): 181-197.

Rowe, R.D., W.D. Schulze, and W. Breffle (1996), 'A test for payment card biases', Journal of Environmental Economics and Management 31(2): 178-185.

Ryan, M., D.A. Scott, and C. Donaldson (2004), 'Valuing health care using willingness to pay: a comparison of the payment card and dichotomous choice methods', Journal of Health Economics 23(2): 237-258.

Samnaliev, M., T.H. Stevens, and T. More (2006), 'A comparison of alternative certainty calibration techniques in contingent valuation', Ecological Economics 57(3): 507-519.

Shaikh, S., L. Sun, and G.C. van Kooten (2007), 'Treating respondent uncertainty in contingent valuation: a comparison of empirical treatments', Ecological Economics 62(1): 115-125.

Shechter, M. and M. Kim (1991), 'Valuation of pollution abatement benefits: direct and indirect measurement', Journal of Urban Economics 30(2): 133-152.

Strazzera, E., M. Genius, R. Scarpa, and G. Hutchinson (2003), 'The effect of protest votes on the estimates of WTP for use values of recreational sites', Environmental and Resource Economics 25(4): 461-476.

van Kooten, G.C., E. Krcmar, and E.H. Bulte (2001), 'Preference uncertainty in nonmarket valuation: a fuzzy approach', American Journal of Agricultural Economics 83(3): 487-500.

Vliet, E.D.S. and P.L. Kinney (2007), 'Impacts of roadway emissions on urban particulate matter concentrations in sub-Saharan Africa: new evidence from Nairobi, Kenya', Environmental Research Letters 2(4): 1-5.

Vossler, C.A., R.G. Ethier, G.L. Poe, and M.P. Welsh (2003), 'Payment certainty in discrete choice contingent valuation responses: results from a field validity test', Southern Economic Journal 69(4): 886-902.

Wang, H. (1997), 'Treatment of "Don't-Know" responses in contingent valuation surveys: a random valuation model', Journal of Environmental Economics and Management 32: 219-232.

Wang, H. and J. He (2011), 'Estimating individual valuation distributions with multiple bounded discrete choice data', Applied Economics 43(21): 2641-2656. 
Wang, H. and J. Mullay (2006), 'Willingness to pay for reducing fatal risk by improving air quality: a contingent valuation study in Chongqing, China', Science of the Total Environment 367(1): 50-57.

Wang, H. and D. Whittington (2000), 'Willingness to pay for air quality improvement in Sofia, Bulgaria', World Bank Policy Research Paper No. 2280, Washington, DC.

Wang, H. and D. Whittington (2005), 'Measuring individuals' valuation distributions using a stochastic payment card approach', Ecological Economics 55(2): 143-154.

Wang, Y. and Y.S. Zhang (2008), 'Air quality assessment by contingent valuation in Ji'nan, China', Journal of Environmental Management 90(2): 1022-1029.

Wang, X.J., W. Zhang, Y. Li, K.Z. Yang, and M. Bai (2006), 'Air quality improvement estimation and assessment using contingent valuation method: a case study in Beijing', Environmental Monitoring and Assessment 120(1): 153-168.

Welsh, M.P. and G.L. Poe (1998), 'Elicitation effects in contingent valuation: comparisons to a multiple bounded discrete choice approach', Journal of Environmental Economics and Management 36(2):170-185.

Wooldridge, J. (2002), Econometric Analysis of Cross Section and Panel Data, Cambridge, MA: MIT Press.

\section{Appendix}

Conventional payment card $(P C)$

\begin{tabular}{cc}
\hline & Value \\
\hline$\square$ & KSh.0 \\
$\square$ & KSh.25 \\
$\square$ & KSh.50 \\
$\square$ & KSh.75 \\
$\square$ & KSh.100 \\
$\square$ & KSh.150 \\
$\square$ & KSh.200 \\
$\square$ & KSh.250 \\
$\square$ & KSh.300 \\
$\square$ & KSh.400 \\
$\square$ & KSh.500 \\
$\square$ & KSh.800 \\
$\square$ & KSh.1000 \\
$\square$ & KSh.1500 \\
$\square$ & KSh.2000 \\
\hline
\end{tabular}


Stochastic payment card (SPC)

\begin{tabular}{lccccccccccccc}
\hline & $\begin{array}{c}\text { Definitely } \\
\text { Value }\end{array}$ & yes & \multicolumn{1}{c}{ Probably yes } & Not sure & Probably no & $\begin{array}{c}\text { Definitely } \\
\text { no }\end{array}$ \\
\hline KSh. 0 & 1.0 & 0.9 & 0.8 & 0.7 & 0.6 & 0.5 & 0.4 & 0.3 & 0.2 & 0.1 & 0 \\
KSh. 25 & 1.0 & 0.9 & 0.8 & 0.7 & 0.6 & 0.5 & 0.4 & 0.3 & 0.2 & 0.1 & 0 \\
KSh. 50 & 1.0 & 0.9 & 0.8 & 0.7 & 0.6 & 0.5 & 0.4 & 0.3 & 0.2 & 0.1 & 0 \\
KSh. 75 & 1.0 & 0.9 & 0.8 & 0.7 & 0.6 & 0.5 & 0.4 & 0.3 & 0.2 & 0.1 & 0 \\
KSh. 100 & 1.0 & 0.9 & 0.8 & 0.7 & 0.6 & 0.5 & 0.4 & 0.3 & 0.2 & 0.1 & 0 \\
KSh. 150 & 1.0 & 0.9 & 0.8 & 0.7 & 0.6 & 0.5 & 0.4 & 0.3 & 0.2 & 0.1 & 0 \\
KSh. 200 & 1.0 & 0.9 & 0.8 & 0.7 & 0.6 & 0.5 & 0.4 & 0.3 & 0.2 & 0.1 & 0 \\
KSh. 250 & 1.0 & 0.9 & 0.8 & 0.7 & 0.6 & 0.5 & 0.4 & 0.3 & 0.2 & 0.1 & 0 \\
KSh. 300 & 1.0 & 0.9 & 0.8 & 0.7 & 0.6 & 0.5 & 0.4 & 0.3 & 0.2 & 0.1 & 0 \\
KSh. 400 & 1.0 & 0.9 & 0.8 & 0.7 & 0.6 & 0.5 & 0.4 & 0.3 & 0.2 & 0.1 & 0 \\
KSh. 500 & 1.0 & 0.9 & 0.8 & 0.7 & 0.6 & 0.5 & 0.4 & 0.3 & 0.2 & 0.1 & 0 \\
KSh. 800 & 1.0 & 0.9 & 0.8 & 0.7 & 0.6 & 0.5 & 0.4 & 0.3 & 0.2 & 0.1 & 0 \\
KSh. 1000 & 1.0 & 0.9 & 0.8 & 0.7 & 0.6 & 0.5 & 0.4 & 0.3 & 0.2 & 0.1 & 0 \\
KSh. 1500 & 1.0 & 0.9 & 0.8 & 0.7 & 0.6 & 0.5 & 0.4 & 0.3 & 0.2 & 0.1 & 0 \\
KSh. 2000 & 1.0 & 0.9 & 0.8 & 0.7 & 0.6 & 0.5 & 0.4 & 0.3 & 0.2 & 0.1 & 0 \\
\hline
\end{tabular}

Polychotomous payment card (PPC)

\begin{tabular}{lccccc}
\hline Value & Definitely yes & Probably yes & Not sure & Probably no & Definitely no \\
\hline KSh. 0 & $\square$ & $\square$ & $\square$ & $\square$ & $\square$ \\
KSh. 25 & $\square$ & $\square$ & $\square$ & $\square$ & $\square$ \\
KSh. 50 & $\square$ & $\square$ & $\square$ & $\square$ & $\square$ \\
KSh. 75 & $\square$ & $\square$ & $\square$ & $\square$ & $\square$ \\
KSh. 100 & $\square$ & $\square$ & $\square$ & $\square$ & $\square$ \\
KSh. 150 & $\square$ & $\square$ & $\square$ & $\square$ & $\square$ \\
KSh. 200 & $\square$ & $\square$ & $\square$ & $\square$ & $\square$ \\
KSh. 250 & $\square$ & $\square$ & $\square$ & $\square$ & $\square$ \\
KSh. 300 & $\square$ & $\square$ & $\square$ & $\square$ & $\square$ \\
KSh. 400 & $\square$ & $\square$ & $\square$ & $\square$ & $\square$ \\
KSh. 500 & $\square$ & $\square$ & $\square$ & $\square$ & $\square$ \\
KSh. 800 & $\square$ & $\square$ & $\square$ & $\square$ & $\square$ \\
KSh. 1000 & $\square$ & $\square$ & $\square$ & $\square$ & $\square$ \\
KSh. 1500 & $\square$ & $\square$ & $\square$ & $\square$ & $\square$ \\
KSh. 2000 & $\square$ & $\square$ & $\square$ & $\square$ & $\square$ \\
\hline
\end{tabular}

